\title{
Estimation and analysis of the ratio of transpiration to evapotranspiration in forest ecosystems along the North-South Transect of East China
}

\author{
REN Xiaoli ${ }^{1}$, LU Qianqian ${ }^{2}$, HE Honglin ${ }^{1,3}$, ZHANG Li $^{1,3}$, NIU Zhongen ${ }^{1,4}$ \\ 1. Key Laboratory of Ecosystem Network Observation and Modeling, Institute of Geographic Sciences and \\ Natural Resources Research, CAS, Beijing 100101, China; \\ 2. Zhongke Tongde (Beijing) Ecology Technology Co., Beijing 100124, China; \\ 3. College of Resources and Environment, University of Chinese Academy of Sciences, Beijing 100190, China; \\ 4. University of Chinese Academy of Sciences, Beijing 100190, China
}

\begin{abstract}
The ratio of transpiration to evapotranspiration (T/ET) is a key parameter for quantifying water use efficiency of ecosystems and understanding the interaction between ecosystem carbon uptake and water cycling in the context of global change. The estimation of T/ET has been paid increasing attention from the scientific community in recent years globally. In this paper, we used the Priestly-Taylor Jet Propulsion Laboratory Model (PT-JPL) driven by regional remote sensing data and gridded meteorological data, to simulate the T/ET in forest ecosystems along the North-South Transect of East China (NSTEC) during 2001-2010, and to analyze the spatial distribution and temporal variation of T/ET, as well as the factors influencing the variation in T/ET. The results showed that: (1) The PT-JPL model is suitable for the simulation of evapotranspiration and its components of forest ecosystems in Eastern China, and has relatively good stability and reliability. (2) Spatial distribution of T/ET in forest ecosystems along NSTEC was heterogeneous, i.e., T/ET was higher in the north and lower in the south, with an averaged value of 0.69 ; and the inter-annual variation of T/ET showed a significantly increasing trend, with an increment of $0.007 / y r(p<0.01)$. (3) Seasonal and inter-annual variations of T/ET had different dominant factors. Temperature and EVI can explain around $90 \%(p<0.01)$ of the seasonal variation in T/ET, while the inter-annual variation in T/ET was mainly controlled by EVI $(53 \%, p<0.05)$.
\end{abstract}

Keywords: The North-South Transect of East China (NSTEC); forest ecosystems; ratio of transpiration to evapotranspiration (T/ET); water use efficiency (WUE)

\section{Introduction}

Global change brought the change in precipitation pattern, which has led to a series of ecological and environmental problems such as the shortage of freshwater resources. In the

Received: 2018-08-22 Accepted: 2018-10-20

Foundation: National Key Research and Development Program of China, No.2015CB954102; National Natural Science Foundation of China, No.31700417, No.41571424

Author: Ren Xiaoli (1984-), PhD, E-mail: renxl@igsnrr.ac.cn 
meantime, the demand for water resources has increased rapidly because of the explosive growth of population. The contradiction between these two situations has intensified the global water resource crisis, and threatened the survival and sustainable development of human society. The earth's surface freshwater resources mainly come from the atmospheric precipitation, about $60 \%$ of which returns to the atmosphere through ecosystem evapotranspiration (Maxwell et al., 2016). Terrestrial ecosystem evapotranspiration (ET) includes interception evaporation, soil evaporation, and canopy transpiration (T) (Fish et al., 2008; Zhu et al., 2015; Maxwell et al., 2016). The global mean value of the ratio between $\mathrm{T}$ and ET (T/ET) is around 60\% (Miralles et al., 2011; Jasechko et al., 2013; Schlesinger et al., 2014; Berkelhammer et al., 2016; Maxwell et al., 2016; Fatichi et al., 2017; Wei et al., 2017), indicating that $\mathrm{T}$ is the largest component of ET. Enhancing the water use efficiency of vegetation transpiration (WUE, GPP/T) is of great significance to alleviate the current water resource crisis (Cheng et al., 2017). However, as it is relatively difficult to obtain the observation data of vegetation transpiration (Scott et al., 2017; Wei et al., 2017), researchers mostly studied the ecosystem water use efficiency (EWUE, GPP/ET) by replacing T with ET (Hu et al., 2009; Gao et al., 2014), which led to the underestimation of WUE. The accurate estimation of $\mathrm{T} / \mathrm{ET}$ is an important premise for quantification and understanding the spatio-temporal characteristics of WUE (Gao et al., 2014). In addition, due to the coupling between vegetation transpiration and photosynthesis, T/ET is also a key factor to understand the carbon and water cycles in the context of global change (Fatichi et al., 2017; Wei et al., 2017). Therefore, T/ET has received extensive attention in recent years, and many studies have reported T/ET of different ecosystem types globally (Coenders-Gerrits et al., 2014; Berkelhammer et al., 2016; Maxwell et al., 2016; Zhou et al., 2016; Fatichi et al., 2017; Scott et al., 2017; Wei et al., 2017). However, studies on the T/ET of China's forest ecosystems, especially on regional scale, have rarely been reported (Zhu et al., 2015).

At present, the quantification methods of T/ET mainly include field observation (Wang et al., 2014; Zhou et al., 2016), isotopic tracing (Coenders-Gerrits et al., 2014; Good et al., 2015), remote sensing model estimation (Zhu et al., 2015; Miralles et al., 2016), and process-based model simulation (Lawrence et al., 2007; Wang-Erlandsson et al., 2014). Although most studies have shown that $\mathrm{T}$ is the largest component of ET, yet the global T/ET estimated by different methods still has large uncertainty, varied from $20 \%$ to $95 \%$ (Miralles et al., 2011; Jasechko et al., 2013; Schlesinger et al., 2014; Berkelhammer et al., 2016; Fatichi et al., 2017; Wei et al., 2017). Compared with the observed T/ET (about 60\%), the T/ET obtained by process-based model simulation was relatively low. For example, the T/ET simulated by multi-models of CMIP5 (Coupled Model Inter-comparison Project 5) varied between $22 \%-58 \%$, and the mean value was only $43 \%$ (Wei et al., 2017). For the remote sensing models, Miralles et al. (2016) simulated T/ET on global scale using PM-MOD (penman-monteith algorithm behind the official Moderate Resolution Imaging Spectroradiometer without product), GLEAM (Global Land without Amsterdam Model), and PT-JPL (Priestley-Taylor Jet Propulsion Laboratory model), and found that the PT-JPL model had the best performance for most ecosystem types and climatic zones, with the global mean $\mathrm{T} / \mathrm{ET}$ at $56 \%$, close to the observed values, indicating that the PT-JPL model is applicable to the estimation of T/ET. 
The North-South Transect of East China (NSTEC) is a unique continuous vegetation zone that has evident hydrothermal gradient, with temperature and precipitation as the main driving factors. It has the most complete forest vegetation series on the earth, providing a natural experimental area for the simulation and analysis of the spatio-temporal variations of T/ET and the driving factors. Zhu et al. (2015) analyzed the spatio-temporal variations of T/ET in three forest ecosystems in eastern China. However, the spatio-temporal variations of regional T/ET in the NSTEC forests have not yet been reported. Lu et al. (2015) verified the key parameters of the PT-LPJ model for three forest ecosystems on the NSTEC, i.e., Changbaishan broadleaved Korean pine mixed forest (CBS), Qianyanzhou subtropical coniferous plantation (QYZ), and Dinghushan subtropical evergreen broadleaved forest (DHS), and improved the simulation accuracy of ET. However, the simulated transpiration of CBS and DHS sites was not validated due to the scarcity of transpiration observation data. In this paper, the simulation accuracy of transpiration in CBS and DHS sites was further verified, and then the regional ET and its components of the forest ecosystems in the NSTEC were simulated using the PT-JPL model, based on the regional remote sensing data and the gridded meteorological data. Through further collecting ET and T observation data reported in the literature, the accuracy of the regional simulated ET and T was verified, and then the spatio-temporal variations of T/ET in the NSTEC forest ecosystems and the underlying influencing factors were analyzed. The quantification of T/ET could help understand the spatio-temporal variations of the water use efficiency of vegetation transpiration in China's forest ecosystems.

\section{Data and methods}

\subsection{Study area}

The North-South Transect of East China (NSTEC) crosses three climate zones, i.e. tropical, subtropical and temperate (Gao et al., 2013), spanning a wide range of environmental conditions including temperature and precipitation. It has been listed as the 15 th international standard transect by IGBP (International Geosphere-Biosphere Programme). The NSTEC has the most complete forest vegetation series on earth (Figure 1), covering more than half of the total forest area in China, which is an ideal experimental region for the study of the interaction between global change and forest ecosystems.

The Changbaishan broadleaved Korean pine mixed forest (CBS), Qianyanzhou subtropical coniferous plantation (QYZ), and Dinghushan subtropical evergreen broad-leaved forest (DHS) are located on NSTEC from the north to the south (Figure 1), with different hydrothermal conditions and vegetation types. These three sites belong to the ChinaFLUX (Chinese Terrestrial Ecosystem Flux Research Network). The annual average temperature of the three sites is $3.6^{\circ} \mathrm{C}, 17.9^{\circ} \mathrm{C}$, and $21^{\circ} \mathrm{C}$, respectively, and the annual precipitation is $695 \mathrm{~mm}$, $1485 \mathrm{~mm}$, and $1956 \mathrm{~mm}$, respectively. The detailed information about the climate condition and vegetation characteristics of the three sites is referred to Yu et al. (2008) and Lu et al. (2015). 


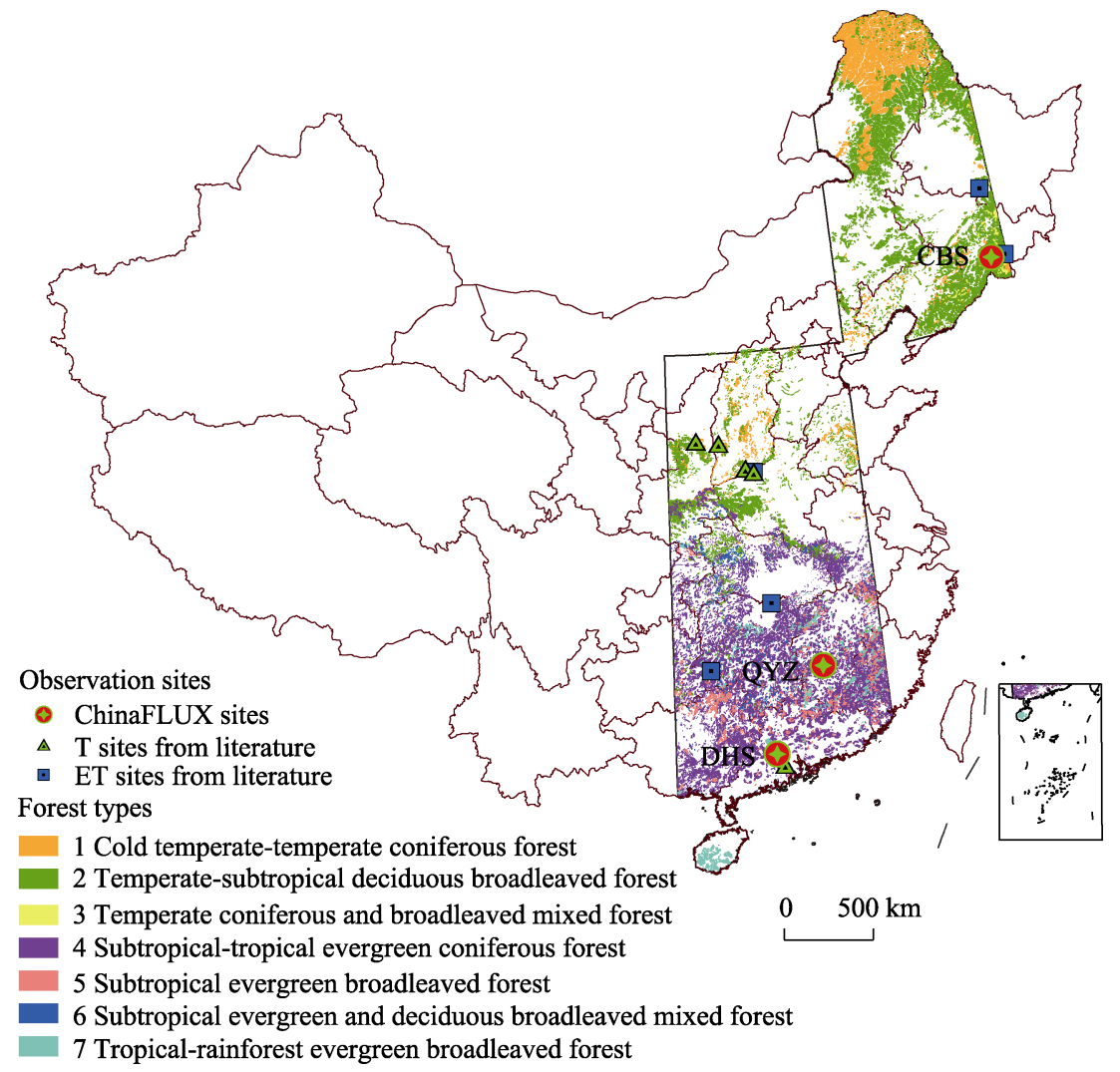

Figure 1 Location of the NSTEC, ChinaFLUX sites and observation sites collected from literature

\subsection{PT-JPL model}

The PT-JPL model (Priestly-Taylor Jet Propulsion Laboratory Model) was an actual ET estimation model proposed by Fisher et al. (2008) based on the Priestley-Taylor equation. ET is partitioned into soil evaporation $\left(E_{s}\right)$, interception evaporation $\left(E_{i}\right)$, and canopy transpiration $(T)$. The driving variables include air temperature $\left(T_{a}\right)$, relative humidity $(R H)$, net radiation $\left(R_{n}\right)$, normalized difference vegetation index (NDVI), and enhanced vegetation index (EVI). These data can be easily acquired, so the PT-JPL model is applicable for regional ET estimation. The main model structure is shown in Equations 1-4, and more detailed information is referred to the literature (Fisher et al., 2008; Wei et al., 2012; Lu et al., 2015).

$$
\begin{gathered}
E T=T+E_{i}+E_{s} \\
T=\left(1-F_{w e t}\right) \cdot F_{g} \cdot F_{m} \cdot \alpha \frac{\Delta}{\Delta+\gamma} R_{n c} \\
E_{i}=F_{\text {wet }} \cdot \alpha \frac{\Delta}{\Delta+\gamma} R_{n c} \\
E_{s}=\left(1-F_{\text {wet }}+F_{s m}\right) \cdot\left(1-F_{w e t}\right) \cdot \alpha \frac{\Delta}{\Delta+\gamma} R_{n s}
\end{gathered}
$$


where $F_{\text {wet }}$ is relative surface wetness, $F_{g}$ is green canopy fraction, $F_{m}$ is plant moisture constraint, $F_{s m}$ is soil moisture constraint, $R_{n c}$ and $R_{n s}$ are net radiation to the canopy and to the soil, respectively, $\alpha$ is Priestley-Taylor constant, $\Delta$ is slope of saturation-to-vapor pressure curve, and $\gamma$ is the psychrometric constant.

\subsection{Basic data}

The basic data used in this study include NDVI, EVI, $T_{a}, R H, R_{n}$, and precipitation of the forest ecosystems in the NSTEC during 2001-2010, as well as the vegetation cover data. Moreover, we collected the transpiration data of CBS, QYZ and DHS sites simulated using Shuttleworth-Wallace model from 2003-2008 by Zhu et al. (2015), which was employed to validate the site-scale transpiration simulation of PT-JPL model. The ET and T data observed in the forest ecosystems of NSTEC reported in the literature were also collected for regional validation of the ET and T estimation of PT-JPL model.

NDVI and EVI were generated based on the MODIS 8-day Land Surface Reflectance dataset (MOD09A1, https://lpdaac.usgs.gov/) (Equations 5 and 6). To reduce the effects of cloud and aerosol, the original time series of NDVI and EVI were smoothed with double logistic curve fit using the TIMESAT software. The spatial climate data $\left(T_{a}, R H, R_{n}\right.$, and precipitation) were interpolated using ANUSPLIN software based on the daily data set produced by the China Meteorological Administration. The spatial resolution of these data was $1 \mathrm{~km} \times 1 \mathrm{~km}$, and the temporal resolution was 8 days.

$$
\begin{gathered}
N D V I=\frac{r_{\text {nir }}-r_{\text {red }}}{r_{\text {nir }}+r_{\text {red }}} \\
E V I=2.5 \times \frac{r_{\text {nir }}-r_{\text {red }}}{r_{\text {nir }}+6 \times r_{\text {red }}-7.5 \times r_{\text {blue }}+1}
\end{gathered}
$$

where $r$ represents reflectance, and the lower case letters of nir, red, and blue represents infrared band, red band and blue band, respectively.

The vegetation cover data were derived from the Atlas of Grassland Resources of China at a scale of 1:1,000,000. The forest ecosystems in the NSTEC were categorized into seven classes (Figure 1), i.e., (1) cold temperate-temperate coniferous forest, (2) temperate-subtropical deciduous broadleaved forest, (3) temperate coniferous and broadleaved mixed forest, (4) subtropical-tropical evergreen coniferous forest, (5) subtropical evergreen broadleaved forest, (6) subtropical evergreen and deciduous broadleaved mixed forest, and (7) tropical-rainforest evergreen broadleaved forest.

\section{Results}

\subsection{Model parameterization and validation}

The accuracy of T/ET depends on the accuracy of the simulated T and ET. Lu et al. (2015) has validated the ET of CBS, QYZ, and DHS forest ecosystems simulated by PT-JPL model. We collected the transpiration data of these three sites simulated by Zhu et al. (2015) using the S-W model, to further validate the PT-JPL model performance for transpiration simulation. The results showed that the transpiration data simulated by the PT-JPL model and S-W model had the similar magnitude and seasonal variation patterns, indicating that there was 
high consistency between the two model results $\left(R^{2}>0.8, p<0.01\right.$, Figure 2$)$. Therefore, The T/ET of the three sites simulated by PT-JPL model had high credibility.

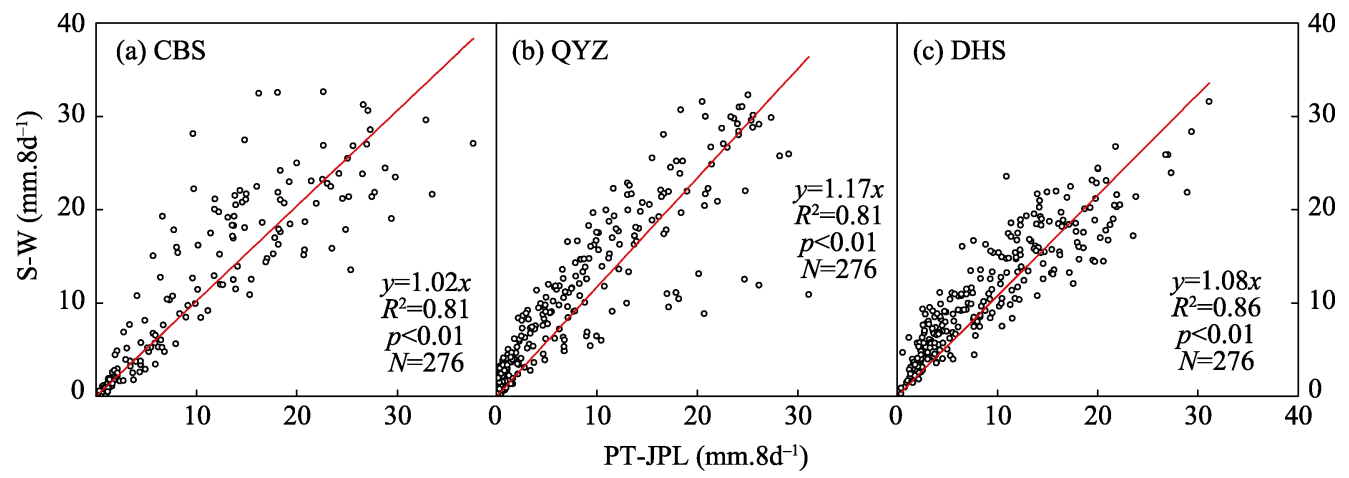

Figure 2 Comparison of the transpiration modeled by the PT-JPL model and the S-W model in CBS, QYZ, and DHS forests during 2003-2008

Different forest types have differences in the climate condition, ecosystem structure, and vegetation characteristics. When using PT-JPL model to simulate the regional T/ET of NSTEC, we set different model parameters for different forest types. The optimum plant growth temperature parameter $\left(T_{\text {opt }}\right)$ was set as the $T_{a}$ when the product of EVI and $T_{a}$ reached the maximum. The plant moisture constraint $\left(F_{m}\right)$ was calculated using the equation of $\left(F_{\text {apar }}+1\right) /\left(F_{\text {aparmax }}+1\right)$, where the $F_{\text {apar }}$ and $F_{\text {aparmax }}$ was the actual and maximum fraction of PAR absorbed by green vegetation cover, respectively (Lu et al., 2015). The parameter $\beta$ in the calculation of soil moisture constraint $\left(F_{s m}=R H^{V P D / \beta}\right)$ and the canopy extinction coefficient $\left(k_{p a r}\right)$ of temperate coniferous and broadleaved mixed forest, subtropical-tropical evergreen coniferous forest, and subtropical evergreen broadleaved forest were determined according to the parameter values optimized for CBS, QYZ, and DHS (Lu et al., 2015). As for the other four forest types, $\beta$ and $k_{\text {par }}$ were determined according to the values reported by Fish et al. (2008) and Zhang et al. (2014). The specific parameter values are shown in Table 1.

Table 1 Determined values of key model parameters for different forest types along the NSTEC

\begin{tabular}{clcc}
\hline ID & \multicolumn{1}{c}{ Forest type } & $\beta$ & $k_{\text {par }}$ \\
\hline 1 & Cold temperate-temperate coniferous forest & 1 & 0.45 \\
2 & Temperate-subtropical deciduous broadleaved forest & 1 & 0.59 \\
3 & Temperate coniferous and broadleaved mixed forest & 1.8 & 0.4 \\
4 & Subtropical-tropical evergreen coniferous forest & 1.5 & 0.3 \\
5 & Subtropical evergreen broadleaved forest & 1.5 & 0.3 \\
6 & Subtropical evergreen and deciduous broadleaved mixed forest & 1 & 0.59 \\
7 & Tropical-rainforest evergreen broadleaved forest & 1 & 0.59 \\
\hline
\end{tabular}

The spatial simulation of ET and T by the PT-JPL model was further verified using the ET and $\mathrm{T}$ observational data collected from the literature (see Figure 1 for the distribution of observation points). By extracting the spatial simulation data of the corresponding locations 
of the observation points, the scatter diagram of the simulated and observed values of T/ET was obtained (Figure 3). We can see that the simulated ET and T were close to the observed values. The $R^{2}$ between the simulated and measured ET values was 0.62, and the RMSE was $135.84 \mathrm{~mm} \mathrm{yr}^{-1}$; the $R^{2}$ of simulated and measured $\mathrm{T}$ values was 0.71 , and the RMSE was $88.07 \mathrm{~mm} \mathrm{yr}^{-1}$. These indicated that the PT-JPL model could be used to simulate the regional ET and its components for forest ecosystems in eastern China.
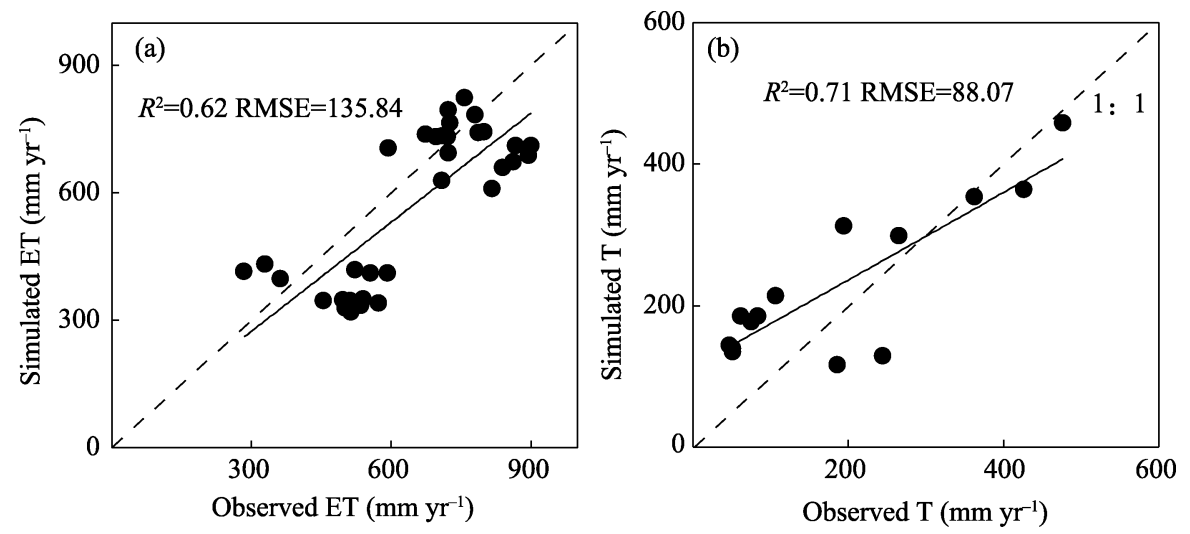

Figure 3 Comparison of the evapotranspiration and transpiration between modeled values by the PT-JPL model and measured values collected from literature

\subsection{Spatial pattern of $\mathrm{T} / \mathrm{ET}$}

The spatial pattern of T/ET of the forest ecosystems in the NSTEC averaged from 2001 to 2010 was inhomogeneous, lower in the south and higher in the north, with an averaged value at 0.69 (Figure 4). Specifically, T/ET was mainly distributed in the range of $0.5-0.8$, and over $90 \%$ of which was in the range of 0.6-0.8, indicating that $\mathrm{T}$ was the main component of ET for most forest ecosystems in the NSTEC. Only less than $1 \%$ of the regional $\mathrm{T} / \mathrm{ET}$ was more than 0.8 or less than 0.5 , and the low-value areas were mainly distributed in the subtropical-tropical evergreen coniferous forests and tropical-rainforest evergreen broadleaved forests along the southern coast. The T/ET increased with the increase in the latitude (Figure 5), with the highest value in the north $\left(>52.5^{\circ}, 0.75\right)$ and the lowest value in the south $\left(20^{\circ} \mathrm{N}-22.5^{\circ} \mathrm{N}, 0.60\right)$. In terms of vegetation types, there were significant dif-

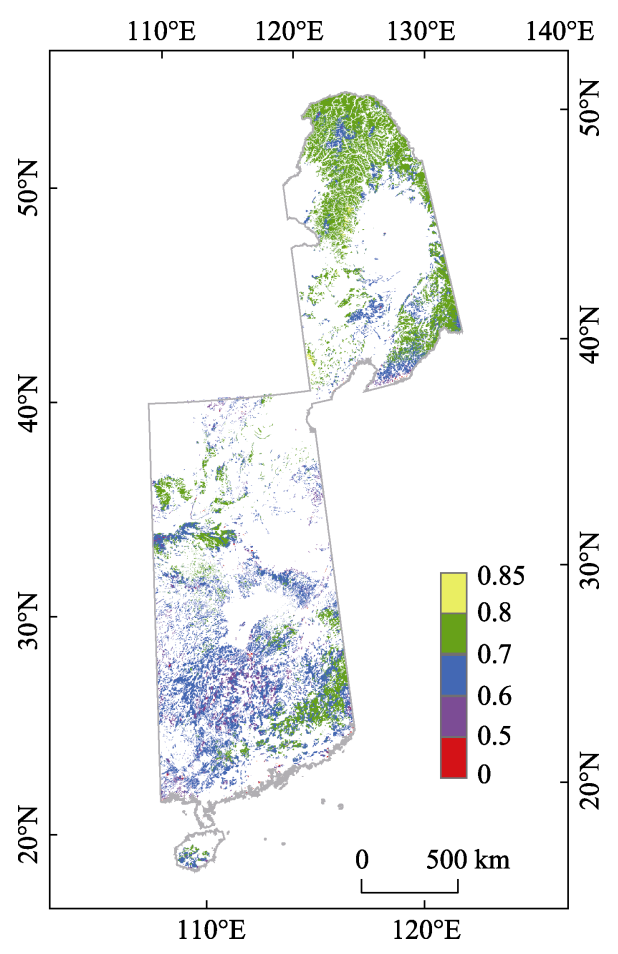

Figure 4 Spatial distribution of averaged T/ET in forests along the NSTEC during 2001-2010 
ferences in T/ET between different vegetation types (Figure 6). The cold temperate-temperate coniferous forest, temperate-subtropical deciduous broadleaved forest, and temperate coniferous and broadleaved mixed forest had the highest T/ET values $(0.71-0.72)$, while the subtropical evergreen and deciduous broadleaved mixed forest had the lowest T/ET values (0.64).

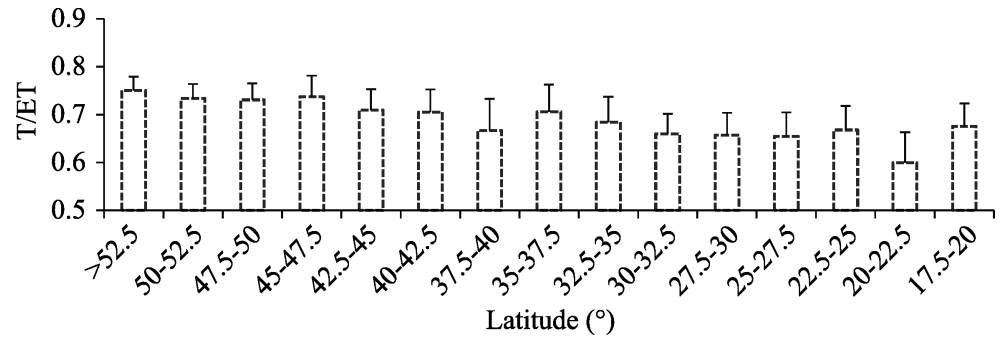

Figure 5 The zonally average T/ET of the forest ecosystems in the NSTEC along latitude

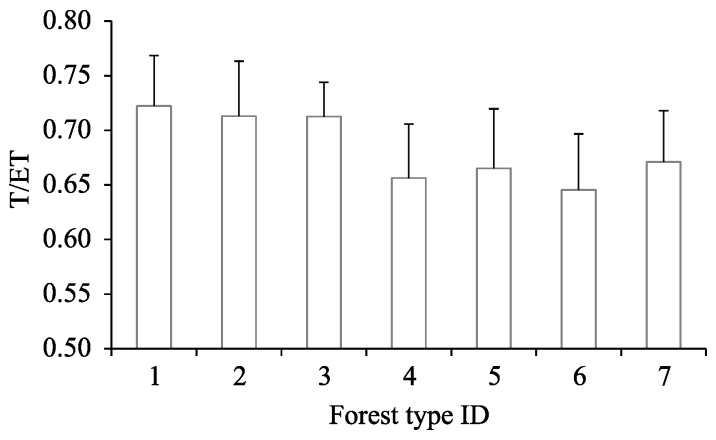

Figure 6 The average T/ET for different forest types (see Table 1 for the specific forest type names represented by ID) along the NSTEC
The spatial patterns of $\mathrm{T} / \mathrm{ET}$ in the NSTEC forest ecosystems showed evident seasonal variations (Figure 7). In winter, the T/ET gradually decreased with the increase in latitude, with an average value of 0.15 . More than $72 \%$ of the area had a T/ET value less than 0.2 , mainly distributed in the deciduous forest ecosystems. About $18 \%$ of the area had the T/ET value be-

tween $0.2-0.4$, which mainly distributed in the subtropical evergreen broadleaved forest ecosystems. Areas with T/ET values above 0.4 were less than $11 \%$ of the NSTEC's total forest area, mainly distributed in tropical forest ecosystems. In spring, T/ET of the NSTEC forest ecosystems was still higher in the south and lower in the north, with an average value of 0.44 . About $95 \%$ of the regional T/ET was within $0.2-0.8$. In summer, the average value of T/ET increased to 0.80 and the spatial difference in T/ET reduced. About $99 \%$ of the regional T/ET values were above 0.6 , and $53 \%$ of the regional T/ET values were above 0.8 . In autumn, the spatial pattern of T/ET was similar to that of spring, decreasing with the increase in latitude, with an average value of 0.55 . Comparing Figure $7 \mathrm{~b}$ with Figure 4 , we can see that the T/ET spatial pattern in summer was most similar to that of the annual averaged $\mathrm{T} / \mathrm{ET}$, indicating that the spatial pattern of the summer T/ET dominated the annual T/ET spatial pattern.

\subsection{Temporal variation of $\mathrm{T} / \mathrm{ET}$}

From 2001 to 2010, the annual average T/ET of the NSTEC forest ecosystems showed a slow and significant upward trend $\left(R^{2}=0.67, p<0.01\right)$, with an average increasing rate of $0.007 / \mathrm{yr}$ (Figure 8a). According to the seasonal average T/ET anomaly curve (Figures 
$8 \mathrm{~b}-8 \mathrm{e}$ ), the T/ET in spring, summer, autumn, and winter all showed an upward trend, with an increasing rate of $0.003 / \mathrm{yr}, 0.005 / \mathrm{yr}, 0.009 / \mathrm{yr}$, and 0.001/yr, respectively. Among them, only the increasing trend in summer was statistically significant $\left(R^{2}=0.39, p=0.05\right)$, and its anomaly curve was most similar to the annual average curve, indicating that the variation of T/ET in summer contributed the most to the inter-annual change of T/ET. The decrease of T/ET in 2003 during summer and autumn caused by El Nino may be one of the reasons why the mean value of T/ET in that year was the lowest among all years (Xu et al., 2014).
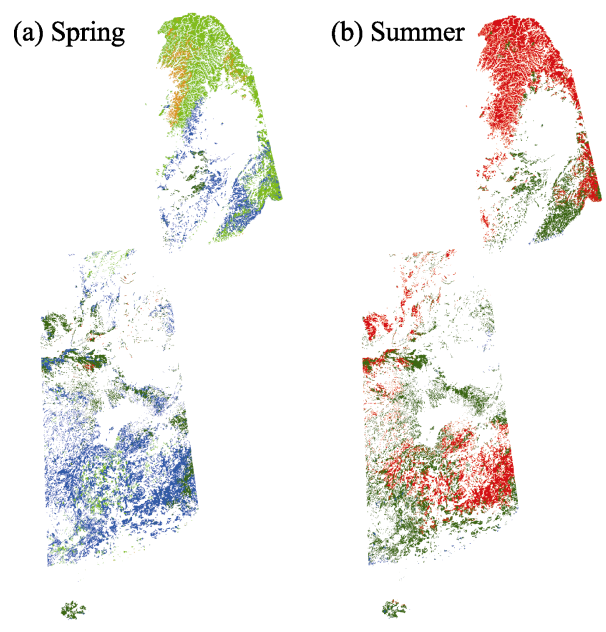

(c) Autumn

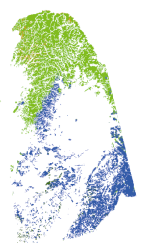

(d) Winter
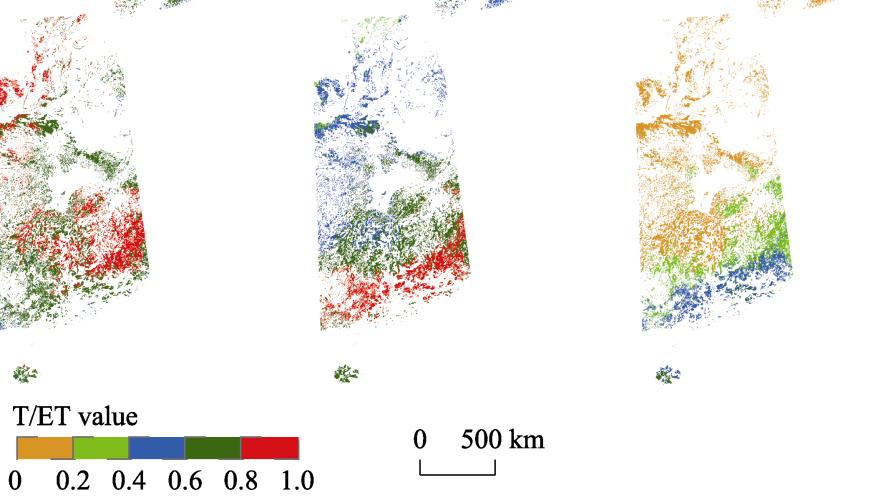

$0 \quad 500 \mathrm{~km}$

Figure 7 Spatial distribution of seasonal average T/ET in forests along the NSTEC during 2001-2010

\subsection{Factors affecting the variations of T/ET}

\subsubsection{Factors affecting the seasonal variation of $\mathrm{T} / \mathrm{ET}$}

The seasonal variation of T/ET in the NSTEC forest ecosystems was positively correlated with the seasonal variations in temperature, precipitation, and EVI (Figure 9). The temperature and EVI were the leading factors of the seasonal variation of T/ET, which could explain $91 \%(p<0.01)$ and $88 \%(p<0.01)$ of T/ET seasonal variation, respectively. While, the impact of precipitation on T/ET seasonal variation was relatively weak. The T/ET values increased with temperature linearly, with $\mathrm{T} / \mathrm{ET}$ increased 0.03 per $1{ }^{\circ} \mathrm{C}$ rise. The relationship between T/ET and EVI was a significantly logarithmic positive correlation. The T/ET showed a linear uptrend when EVI was lower than 0.4. When EVI was higher than 0.4, the increase in T/ET decelerated.

To further understand the impact of temperature, precipitation, and EVI on the seasonal variation of T/ET, Pearson correlation coefficient $(R)$ between T/ET and the three factors at the scale of 8 days was calculated (Figure 10). The seasonal variation of T/ET in most areas of the NSTEC was controlled by temperature and EVI, especially in temperate forests and the forests in north subtropical and south subtropical climates, where the correlation coeffi- 
cient was over 0.8 . The correlation coefficient between T/ET and precipitation did not exceed 0.4 in the entire area of the NSTEC, indicating that precipitation was not the key factor influencing the seasonal variation of T/ET in almost all forest types.

\subsubsection{Factors affecting the inter-annual variation of T/ET}

The annual precipitation and temperature had a very weak impact on the inter-annual variation of T/ET $\left(R^{2}=0.01, p>0.7\right)$ (Figure 11$)$. The T/ET increased significantly with the increase in EVI from 2001 to 2010, with T/ET increased 0.027 per 0.01 increases in EVI. The

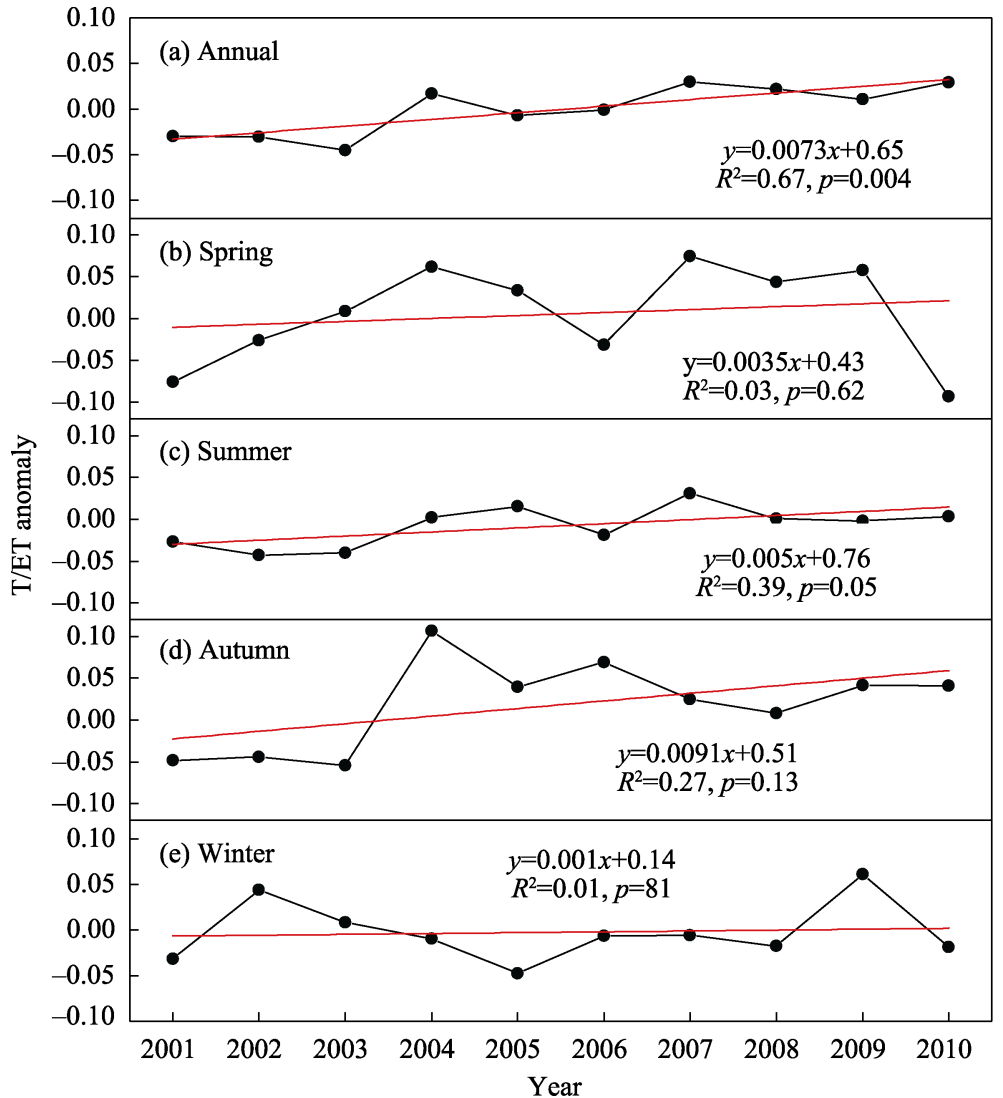

Figure 8 Anomalies of annual and seasonal T/ET averaged over the forests along the NSTEC during 2001-2010
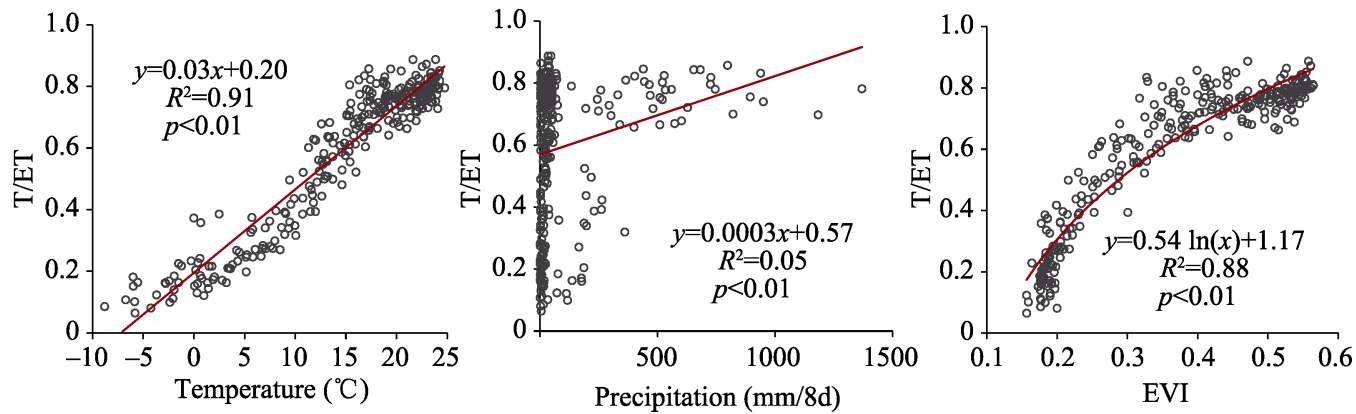

Figure 9 Responses of the modeled seasonal T/ET (8d) to temperature, precipitation, and EVI in the forests along the NSTEC 
(a) Temperature-T/ET

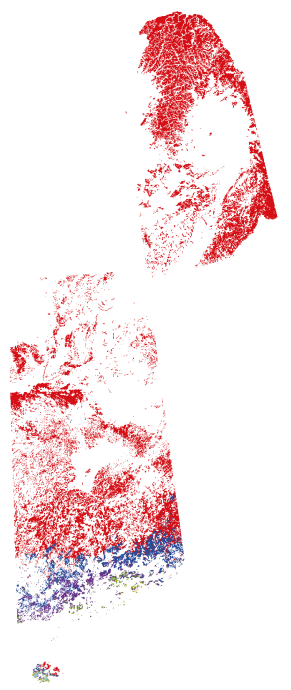

(b) Precipitation-T/ET

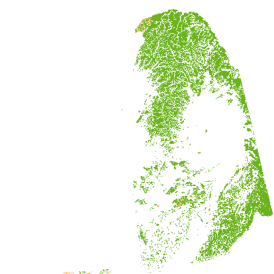

(c) EVI-T/ET

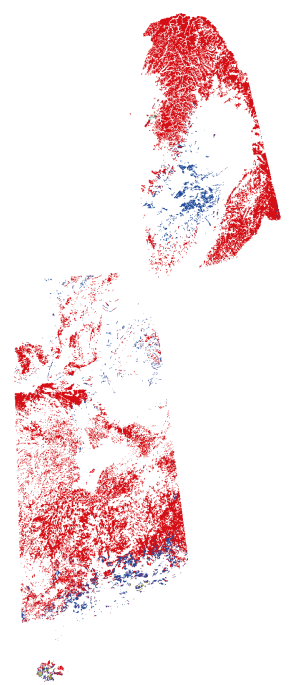

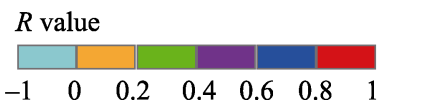

$500 \mathrm{~km}$

Figure 10 Spatial distribution of the correlation coefficient $(R)$ between the modeled seasonal T/ET (8d) to temperature, precipitation, and EVI in forests along the NSTEC
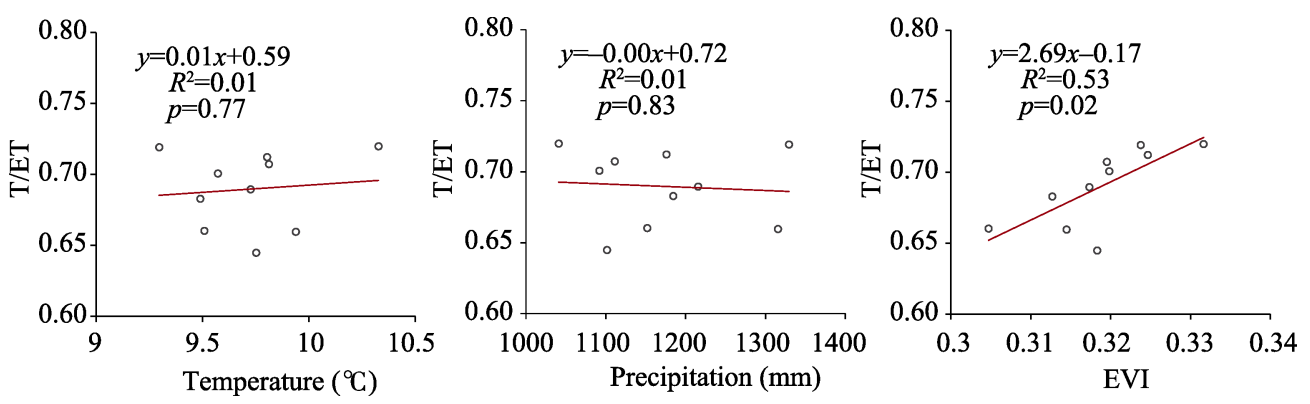

Figure 11 Relationships between the annual T/ET to temperature and precipitation, and EVI in forests along the NSTEC

inter-annual variation in EVI could explain 53\% of the inter-annual variation in T/ET, indicating that the inter-annual variation in EVI was the key factor influencing the inter-annual variation in $\mathrm{T} / \mathrm{ET}$.

The spatial correlation between the inter-annual variation of T/ET in the NSTEC forest ecosystems and the climate and vegetation growth was quantitatively analyzed (Figure 12). Overall, the correlation of T/ET with EVI was the highest, followed by that with temperature and precipitation. About $90 \%$ of the regions showed a positive correlation between annual T/ET and EVI and more than 50\% areas had the T/ET values higher than 0.5 (Figure 12c), indicating that the increase in annual EVI promoted the increase in T/ET. The positive correlation between annual $\mathrm{T} / \mathrm{ET}$ and temperature was reflected in about $80 \%$ of the forest ecosystems, where only less than $20 \%$ area had a correlation coefficient greater than 0.5 , mainly distributed in the central subtropical-tropical evergreen coniferous forest (Figure 12a). The correlation between annual T/ET and precipitation was negative in most areas (nearly 90\%), 
indicating that the increase in precipitation will inhibit T/ET. Only a small part of central and southeastern temperate regions with less than $800 \mathrm{~mm}$ annual precipitation had a positive correlation between T/ET and precipitation (Figure 12b).

(a) Temperature-T/ET

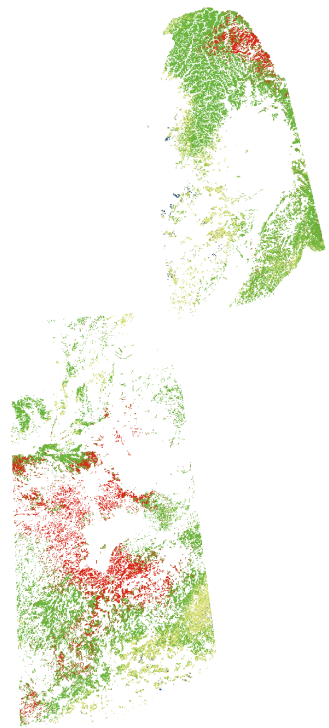

(b) Precipitation-T/ET

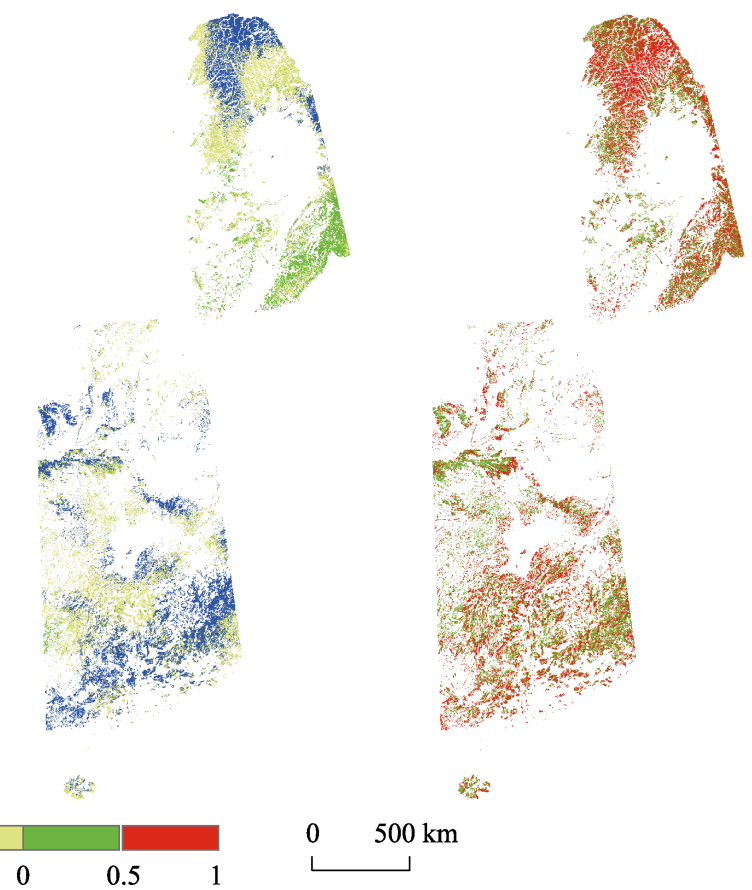

(c) EVI-T/ET

Figure 12 Spatial distribution of the correlation coefficient $(R)$ of the annual T/ET with temperature, precipitation, and EVI in forests along the NSTEC

\section{Discussion}

In recent years, T/ET has been paid more and more attention. Many studies have reported T/ET of the global terrestrial ecosystems was around an average value of about 0.6 (Miralles et al., 2011; Jasechko et al., 2013; Schlesinger et al., 2014; Berkelhammer et al., 2016; Maxwell et al., 2016; Fatichi et al., 2017; Wei et al., 2017). In this paper, the average T/ET value of the forest ecosystems in the NSTEC was estimated at 0.69 , which was close to the global average value. The NSTEC has complicated natural conditions and almost all forest types in China, and different forest types have different ecosystem structure and vegetation physiological processes. So we also analyzed the T/ET of each forest type, and found that the annual values of T/ET of each forest type were all above 0.60 . The cold temperate-temperate coniferous forest, temperate-subtropical deciduous broadleaved forest, and temperate coniferous and broadleaved mixed forest had the relatively high T/ET values (0.71-0.72), and the subtropical evergreen and deciduous broadleaved mixed forest had the lowest T/ET values (0.64). This indicated that canopy transpiration was the most important contributor to ET in eastern China.

Globally, studies on the T/ET of distinct forest types are quite different at present 
(Schlesinger et al., 2014; Wang-Erlandsson et al., 2014; Zhou et al., 2016; Fatichi et al., 2017; Wei et al., 2017). For example, Wang-Erlandsson et al. (2014) simulated the global ET and its components using the STEAM Model and found that deciduous broadleaved forest had the largest T/ET value (0.64), followed by mixed forest and evergreen broadleaved forest $(0.57$ and 0.54$)$, and deciduous and evergreen coniferous forests had the smallest value (0.52 and 0.50). Wei et al. (2017) estimated the T/ET of different global vegetation types by using the empirical relationship between T/ET and leaf area index (LAI), and found that broadleaved forest had larger T/ET (0.61) than mixed forest and coniferous forest $(0.55)$. Based on FLUXNET eddy covariance flux observation data, Zhou et al. (2016) calculated the T/ET of 17 flux sites in the United States by using apparent LUE and potential LUE ratio method, and found that evergreen coniferous forest had larger T/ET than deciduous broadleaved forest ( 0.56 vs 0.52 ), which was contrary to the conclusions of the above two studies. Fatichi et al. (2017) found that T/ET values of different vegetation types around the world were relatively close, almost within the range of $0.70 \pm 0.09$. Although the T/ET of different forest types obtained by different methods was not consistent, the variation range was between 0.50 and 0.79 , and the simulated T/ET of different forest types in this paper (Figure 6, $0.64-0.72$ ) was within the range of existed studies.

The annual T/ET of the NSTEC forest ecosystems increased with the increase in latitude, which was consistent with the global results reported by Wei et al. (2017). Lower T/ET values were mainly distributed in the subtropical-tropical evergreen coniferous forest and tropical-rainforest evergreen broadleaved forest along the southern coast (Figure 4), where the thick canopy, complicated structure, strong ability to store water (Wu et al., 1998), and coastal rainy climate may have caused a higher rate of interception evaporation, thus reduced the contribution of T to ET. In winter, T/ET was relatively low overall, but some areas in tropical forests had T/ET value over 0.4 , which may be due to the relatively more vigorous vegetation physiological activities compared with the northern region. From winter to spring, with the increase in precipitation and the rise in temperature, the transpiration of the southern evergreen forests gradually accelerated and that of the northern deciduous forests gradually recovered, leading to the increase in T/ET. In summer, the forest ecosystems in the NSTEC entered the fast-growing period, so the overall T/ET value was high. In autumn, deciduous forests in the north began to fall into the deciduous period, thus the leaf area for transpiration decreased and vegetation physiological activities weakened. However, the evergreen forests in the south still maintained high transpiration potential, so the T/ET showed a trend of gradually decrease with the increase in latitude.

T/ET involves two ecosystem processes, i.e. vegetation transpiration and evaporation, which are affected by environmental factors such as solar radiation, air temperature, air humidity, precipitation, wind speed, soil moisture (Wang et al., 2012; Zhu et al., 2015) and biological factors such as vegetation growth, vegetation type and LAI (Wang et al., 2012; Jasechko et al., 2013; Wang et al., 2014). This paper quantitatively analyzed the influences of environmental factors (temperature and precipitation) and biological factors (EVI) on the variations of T/ET of the forest ecosystems in the NSTEC, and found that the annual variation of T/ET was mainly dominated by EVI. Hu et al. (2009) and Zhu et al. (2015) also reported the main controlling effect of vegetation growth on the inter-annual change of T/ET. As for the seasonal variation of T/ET, we found that it was mainly dominated by temperature 
and EVI. Temperature influenced the seasonal variation of T/ET through adjusting the stomatal conductance of leaves (Hu et al., 2009; Yu and Wang, 2010; Zhu et al., 2015). The increase of EVI means the increase of leaf area for vegetation transpiration, thus more radiation intercepted by canopy and less radiation reaching the surface. This led to the increase of water consumption by transpiration and the decrease of water consumption by evaporation, which promoted the increase of T/ET. However, when EVI is relatively large, it will continue to increase the interception evaporation of canopy, but will also reduce soil evaporation. These two effects offset each other (Fatichi et al., 2017), leading to less effect of EVI on T/ET. Therefore, the T/ET and EVI showed a nonlinear relationship (Figure 9c). Similarly, Zhou et al. (2016) found that the seasonal variation of EVI was significantly correlated with that of T/ET, which could explain $75 \%$ of the seasonal variation of T/ET, and Fatichi et al. (2017) also found that the seasonal variation of T/ET was significantly correlated with the vegetation growth.

The impact factor analysis of T/ET in this paper adopted the univariate correlation analysis method, whereas the interaction between temperature, precipitation, and EVI may affect the accuracy of the conclusion. Therefore, we further analyzed the influencing factors of T/ET using partial correlation analysis method, and the results showed that temperature and EVI were still the dominant factors of T/ET seasonal variation (temperature: $R^{2}=0.53$, $p<0.0001$; precipitation: $R^{2}=0.00, p=0.93$; EVI: $R^{2}=0.02, p<0.05$ ), although the effect of EVI decreased significantly, indicating that the influence of EVI was largely due to its correlation with temperature. The leading factor for the inter-annual variation of T/ET was still EVI (temperature: $R^{2}=0.19, p=0.29$; precipitation: $R^{2}=0.00, p=0.91$; EVI: $R^{2}=0.62, p<0.05$ ). The correlation between the influencing factors does interfere with the analysis results, but the main conclusions are not affected. In addition, the structural equation model can further analyze the causal relationship between variables, which is also an effective method to analyze the factors influencing T/ET (Quan et al., 2018). Other environmental factors, such as soil moisture, vapor pressure deficit, and wind speed, all have influences on T/ET, while the impact of these factors has not been analyzed in this paper. In the future, we should collect more data and use the structural equation model to further analyze the variation of T/ET of the eastern forest ecosystems of China and its influencing factors.

\section{Conclusions}

We simulated the spatial T/ET of the forest ecosystems in the NSTEC during 2001-2010 using PT-JPL model based on remote sensing data and spatial meteorological data, and analyzed the spatial distribution and temporal variation of T/ET in the NSTEC forest ecosystems. We also explored the environmental and biological factors (temperature, precipitation, and EVI) that influenced the inter-annual and seasonal variations of T/ET in the NSTEC forest ecosystems. The main conclusions are as follows:

(1) The PT-JPL model was suitable for the simulation of ET and its components for the forest ecosystems in eastern China, with high stability and reliability, through multi-site verification.

(2) The annual T/ET of the NSTEC forest ecosystems averaged from 2001 to 2010 showed significant spatial inhomogeneity, lower in the south and higher in the north, with an 
average value at 0.69 .

(3) The annual and seasonal T/ET of the NSTEC forest ecosystems all showed an increasing trend from 2001 to 2010. Among them, the trends of annual and summer T/ET was statistically significant, with increasing rate at $0.007 / \mathrm{yr}$ and $0.005 / \mathrm{yr}$, respectively.

(4) The main influencing factors of the annual and seasonal variations of T/ET in the NSTEC forest ecosystems were different, with seasonal variation mainly affected by temperature and EVI and the inter-annual variation mainly affected by EVI.

\section{Acknowledgement}

The flux data of CBS, QYZ, DHS sites were obtained from ChinaFLUX, and the simulated transpiration data of the three sites were provided by Dr. Xianjin Zhu and Prof. Guirui Yu, which are highly acknowledged.

\section{References}

Berkelhammer M, Noone D C, Wong T E et al., 2016. Convergent approaches to determine an ecosystem's transpiration fraction. Global Biogeochemical Cycles, 30(6): 933-951.

Cheng L, Zhang L, Wang Y P et al., 2017. Recent increases in terrestrial carbon uptake at little cost to the water cycle. Nature Communications, 8: 110. doi: 10.1038/s41467-017-00114-5.

Coenders-Gerrits A M J, van der Ent R J, Bogaard T A et al., 2014. Uncertainties in transpiration estimates. Nature, 506(7487): E1-E2.

Fatichi S, Pappas C, 2017. Constrained variability of modeled T:ET ratio across biomes. Geophysical Research Letters, 44(13): 6795-6803.

Fisher J B, Tu K P, Baldocchi D D, 2008. Global estimates of the land-atmosphere water flux based on monthly AVHRR and ISLSCP-II data, validated at 16 FLUXNET sites. Remote Sensing of Environment, 112(3): 901-919.

Gao Y H, Liu X X, Min C C et al., 2013. Estimation of the North-South Transect of Eastern China forest biomass using remote sensing and forest inventory data. International Journal of Remote Sensing, 34(15): 5598-5610.

Gao Y, Zhu X J, Yu G R et al., 2014. Water use efficiency threshold for terrestrial ecosystem carbon sequestration in China under afforestation. Agricultural and Forest Meteorology, 195: 32-37. doi: 10.1016/j.agrformet. 2014.04.010.

Good S P, Noone D, Bowen G, 2015. Hydrologic connectivity constrains partitioning of global terrestrial water fluxes. Science, 349(6244): 175-177.

Hu Z M, Yu G R, Wang Q F et al., 2009a. Ecosystem level water use efficiency: A review. Acta Ecologica Sinica, 29(3): 1498-1507. (in Chinese)

$\mathrm{Hu}$ Z M, Yu G R, Zhou Y L et al., 2009b. Partitioning of evapotranspiration and its controls in four grassland ecosystems: Application of a two-source model. Agricultural and Forest Meteorology, 149(9): 1410-1420.

Jasechko S, Sharp Z D, Gibson J J et al., 2013. Terrestrial water fluxes dominated by transpiration. Nature, 496(7445): 347-351.

Lawrence D M, Thornton P E, Oleson K W et al., 2007. The partitioning of evapotranspiration into transpiration, soil evaporation, and canopy evaporation in a GCM: Impacts on land-atmosphere interaction. Journal of Hydrometeorology, 8(4): 862-880.

Lu Q Q, He H L, Zhu X J et al., 2015. Study on the variations of forest evapotranspiration and its components in eastern China. Journal of Natural Resources, 30(9): 1436-1448. (in Chinese)

Maxwell R M, Condon L E, 2016. Connections between groundwater flow and transpiration partitioning. Science, 353(6297): 377-380.

Miralles D G, De Jeu R A M, Gash J H et al., 2011. Magnitude and variability of land evaporation and its compo- 
nents at the global scale. Hydrology and Earth System Sciences, 15(3): 967-981.

Miralles D G, Jimenez C, Jung M et al., 2016. The WACMOS-ET project - Part 2: Evaluation of global terrestrial evaporation data sets. Hydrology and Earth System Sciences, 20(2): 823-842.

Quan Q, Zhang F Y, Tian D S et al., 2018. Transpiration dominates ecosystem water-use efficiency in response to warming in an alpine meadow. Journal of Geophysical Research-Biogeosciences, 123(2): 453-462.

Schlesinger W H, Jasechko S, 2014. Transpiration in the global water cycle. Agricultural and Forest Meteorology, 189: 115-117. doi: 10.1016/j.agrformet.2014.01.011.

Scott R L, Biederman J A, 2017. Partitioning evapotranspiration using long-term carbon dioxide and water vapor fluxes. Geophysical Research Letters, 44(13): 6833-6840.

Wang-Erlandsson L, van der Ent R J, Gordon L J et al., 2014. Contrasting roles of interception and transpiration in the hydrological cycle - Part 1: Temporal characteristics over land. Earth System Dynamics, 5(2): 441-469.

Wang K C, Dickinson R E, 2012. A Review of Global Terrestrial Evapotranspiration: Observation, Modeling, Climatology, and Climatic Variability. Reviews of Geophysics, 50: RG2005. doi: 10.1029/2011RG000373.

Wang L X, Good S P, Caylor K K, 2014. Global synthesis of vegetation control on evapotranspiration partitioning. Geophysical Research Letters, 41(19): 6753-6757.

Wei H Q, He H L, LIu M et al., 2012. Modeling evapotranspiration and its components in Qianyanzhou plantation based on remote sensing data. Journal of Natural Resources, 27(5): 778-789. (in Chinese)

Wei Z W, Yoshimura K, Wang L X et al., 2017. Revisiting the contribution of transpiration to global terrestrial evapotranspiration. Geophysical Research Letters, 44(6): 2792-2801.

Wu H S, Liu H P, Huang D J, 1998. Interception of Precipitation in Dinghushan Evergreen Broadleaf Forest. Research of Forest Ecosystems in Subtropical and Tropical Regions. Beijing: China Meteorological Press. (in Chinese)

Xu M J, Wen X F, Wang H M et al., 2014. Effects of climatic factors and ecosystem responses on the inter-annual variability of evapotranspiration in a coniferous plantation in subtropical China. Plos One, 9(1): e85593. doi: 10.1371/journal.pone.0085593.

Yu G R, Wang Q F, 2010. Ecophysiology of Plant Photosynthesis, Transpiration, and Water Use. Beijing: Science Press. (in Chinese)

Yu G R, Zhang L M, Sun X M et al., 2008. Environmental controls over carbon exchange of three forest ecosystems in eastern China. Global Change Biology, 14(11): 2555-2571.

Zhang L X, Hu Z M, Fan J W et al., 2014. A meta-analysis of the canopy light extinction coefficient in terrestrial ecosystems. Frontiers of Earth Science, 8(4): 599-609.

Zhou S, Yu B F, Zhang Y et al., 2016. Partitioning evapotranspiration based on the concept of underlying water use efficiency. Water Resources Research, 52(2): 1160-1175.

Zhu X J, Yu G R, Hu Z M et al., 2015. Spatiotemporal variations of T/ET (the ratio of transpiration to evapotranspiration) in three forests of eastern China. Ecological Indicators, 52: 411-421. doi: 10.1016/j.ecolind. 2014.12.030. 